\title{
Evaluation of Factors Influencing Medication Adherence in Patients with Epilepsy in Rural Communities of Kaduna State, Nigeria
}

\author{
Ogboi Sonny Johnbull ${ }^{1 *}$, Babajide Farounbi ${ }^{2}$, Ademola O. Adeleye ${ }^{2}$, Olabunmi Ogunrin ${ }^{3}$, \\ Agu P. Uche ${ }^{4}$

\begin{abstract}
${ }^{1}$ Department of Community Medicine, Faculty of Medicine, Ahmadu Bello University, Zaria, Nigeria; ${ }^{2}$ General Outpatient Department, Ahmadu Bello University Teaching Hospital Zaria, Nigeria/Jicon Hospital, Kaduna, Nigeria; ${ }^{3}$ University of Benin Teaching Hospital, Benin-City, Nigeria; ${ }^{4}$ Department of Obstetrics and Gynaecology, University of Nigeria Teaching Hospital, Ituku-Ozalla, Enugu, Nigeria.
\end{abstract} \\ E-mail: *ogboijb@yahoo.com
}

Received September $13^{\text {th }}$, 2011; revised November $7^{\text {th }}$, 2011; accepted November $20^{\text {th }}, 2011$.

\begin{abstract}
Background and Objective: Adherence to medication is the backbone to effectiveness of a therapy. In the absence of a definitive curative therapy, antiepileptic therapy is a key intervention aimed at prolonging and improving the quality of life of patients with epilepsy (PWE) who suffer from a disease known for its stigmatization with many cultural misconceptions. The aim of the study is to assess the level of, and factors influencing adherence to antiepileptic therapy among patients in rural communities attending the outpatient clinics in Ahmadu Bello University Teaching Hospital, Zaria and Jicon Hospital, Kaduna, Northern Nigeria. Materials and Methodology: A cross-sectional descriptive study design was used. Interviewer-administered, structured questionnaires were administered to a sample of 272 PWE attending Ahmadu Bello University Teaching Hospital/Jicon Hospital Kaduna, who had been on antiepileptic drugs (AEDs) for at least one year. Systematic random sampling technique was used to select the patients. Information was obtained on their knowledge of epilepsy and adherence to antiepileptic therapy regimen as well as factors influencing adherence to AED regimen. Results: The level of knowledge of epilepsy based on signs and symptoms was high as $57.8 \%$ and $25.9 \%$ of the PWE had excellent and good knowledge respectively. Also, most of the PWE (78.6\%) had adequate knowledge of antiepileptic therapy, however only $32.6 \%$ of the patients were adherent to treatment. There was a significant association between knowledge of AED therapy and adherence to therapy $(p=0.00385)$ but there was no association between age $(p=0.067)$, sex $(p=0.182)$ educational status $(p=0.688)$, income $(p=0.519)$ religion $(p=0.69)$, place of residence $(p=0.157)$ with AED adherence. The reasons for non-adherence included forgetfulness, drug-induced fatigue and being away from home. Conclusion: This study showed that patients with epilepsy had adequate knowledge of epilepsy and its treatment. Medication adherence was demonstrated to be low due to forgetfulness, fatigue and being away from home. We therefore recommend adherence counseling in the clinic and health educational interventions to improve adherence in our rural communities. Further exploration of the relationship between clinical outcomes and other non-drug self-management strategies is needed.
\end{abstract}

Keywords: Epilepsy, Medications, Adherence, Kaduna, Nigeria

\section{Introduction}

Epilepsy is the most common serious neurological disorder and is one of the world's most prevalent noncommunicable diseases. It is estimated that the condition affects approximately 50 million people, around 40 million of them living in developing countries $[1,2]$. The incidence of epilepsy in low-income countries may be as high as 190 per 100,000 people [3]. Consequently, in the context of the large and rapidly increasing populations in these countries, epilepsy is a significant health and socioeconomic burden requiring urgent attention [4]. Against this background, the World Health Organization's (WHO) aim of easing the burden of mental and neurological ill- 
nesses that affect 400 million people [5] worldwide is timely. About $90 \%$ of people with epilepsy in developing countries are not receiving appropriate treatment. Consequently, people with epilepsy continue to be stigmatized and have a lower quality of life than people with other chronic illnesses [6]. However, bridging the treatment gap and reducing the burden of epilepsy is not straightforward and faces many constraints. Cultural attitudes, lack of prioritization, poor health system infrastructure, and inadequate supplies of antiepileptic drugs all conspire to hinder appropriate treatment as epilepsy is perceived as an ancestral spirits/possession by evil spirits by most Africans. Nevertheless, there have been successful attempts to provide treatment, which have shown the importance of community-based approaches and also indicate that provision for sustained intervention over the long term is necessary in any treatment programme. Adherence to medication is the backbone to effectiveness of a therapy. In the absence of a definitive curative therapy, antiepileptic therapy is a key intervention aimed at prolonging and improving the quality of life of epileptic patients suffering from a disease known for its stigmatization with many cultural misconceptions. The aim of the study is to assess the level of knowledge of epilepsy, and factors influencing adherence to antiepileptic therapy among patients in rural communities attending outpatient clinic in Ahmadu Bello University Teaching Hospital, Zaria and Jicon Hospital, Kaduna, northern Nigeria.

\section{Materials and Methodology}

\subsection{Study Design}

This is a cross-sectional study that utilized intervieweradministered, structured questionnaires to obtain information from a sample of 272 patients with epilepsy attending Ahmadu Bello University Teaching Hospital/ Jicon Hospital Kaduna, who had been on antiepileptic drug (AED) for at least one year. Systematic random sampling technique was used to select the patients. Information was obtained on their knowledge of epilepsy and antiepileptic therapy regimen adherence to AED and factors influencing adherence to AED regimen.

\subsection{Study Population}

All patients with epilepsy (PWE) registered in the Antiepileptic Clinic of Ahmadu Bello University/Jicon Hospital Kaduna who had been on treatment for a minimum of one (1) year prior to the onset of the study constituted the study population. Patients included in this study were adults with confirmed diagnosis of epilepsy who were registered with Ahmadu Bello University Teaching Hospital/Jicon Hospital Kaduna and had com- menced treatment with the centre for a minimum of one (1) year. They included those patients that had been on antiepileptic drugs in some rural centres but transferred to the Ahmadu Bello University Teaching Hospital/Jicon Hospital Kaduna for the continuation and supply of drugs.

The exclusion criteria included patients below the age of 14 years, new patients with less than 3 months of medication and mentally ill patients because they could not comprehend the importance of adherence and might even not take the medication at all.

\subsection{Sampling Size Determination}

A recent review of adherence to antiepileptic drugs (AEDs) reported figures ranging from $28 \%-82 \%$ and most of the studies sharing rates between $50 \%$ and $80 \%$. Therefore $80 \%$ was used as $p$-value at a precision of $5 \%$ with $95 \%$ confidence limit at 0.05 level of significance [7].

The sample size of 272 was divided equally among the 4 clinic days in a month. The systematic random sampling strategy was used to select patients on each clinic day until the required number of patients was obtained. The 4 clinic days was also randomly selected. The table of random numbers was used to locate the starting point and the sampling interval was calculated based on the average attendance.

Pre-tested, structured, and mostly closed-ended questionnaires were used for data collection. It was interviewer administered and data were collected over one month period. The questionnaire was in four parts. The first part obtained information on socio-demographic variables such as age, sex, place of residence, ethnicity, religion and educational level, marital status and occupations. The second part obtained information about respondents' knowledge on epilepsy i.e. whether any of their relatives was infected, the transmission of the disease, their opinions about the cause, knowledge about signs and symptoms of the disease, to know if it has a cure or not, and how it can be prevented. The third part was about the knowledge of antiepileptic therapy, the source of their information, when to commence the therapy, knowledge about combination therapy, the duration of treatment, the timing of usage of medication, frequency of dosing and identification of drugs. The fourth part was about the level of adherence to antiepileptic drugs. Patients were to identify the drugs they were taking presently (using the samples obtained from the hospital pharmacy). The number of months they have been on treatment was determined, case notes were crosschecked to know whether the dosages and the frequency with the name of the drugs tally, they were asked to re- 
call the number of times per day they were supposed to take the medication, based on the regimen the hospital is using, the number of pills they take per day and per dose. Patients were then asked to recall the number of doses they missed within the past seven days preceding the interview, and to verify it with the sachets of used drugs they brought to the clinic. Then if he or she has missed any dose the reasons for missing were sought for. Respondents were asked about side effects of the drugs they were using. Enquiries about satisfaction and confidentiality of the clinic setting, waiting time in the hospital and if at any time drug was not available were made. Those without problems or complaints were giving monthly visit for follow up. Eight medical personnel previously trained did the interviews ensuring confidentiality and privacy. Pre-testing of the questionnaire was done on 10 patients at JICON Hospital Kaduna. The results of the pilot study were used to modify the contents and wordings of the questionnaire. The quality assurance in terms of validity and accuracy of the data were done after each day of the interview.

\subsection{Data Analysis}

Data was analyzed using SPSS Version 11, statistical software (SPSS Inc. Chicago, IL). Data was presented in graphs and tables. Absolute numbers and simple percentages were described using measures of central tendency (mean, median) and measures of dispersion (Range, standard Deviation) as appropriate. The Chi-square test was done to assess the strength of association between socio-demographic characteristics and medication adherence on one hand, and between knowledge of epilepsy and adherence on the other. A p-value of 0.05 or less was considered statistical significant.

\subsection{Ethical Consideration}

An ethical approval was obtained from the authority of the Ahmadu Bello University Teaching Hospital/Jicon Hospital Kaduna and verbal consent from the patients before administering the questionnaire. Confidentiality was ensured in the handling of data.

\section{Results}

A total of 272 PWE were studied but 2 patients did not meet the requirements during the final analysis. There were 172 female and 98 male, giving a male: female ratio of 1:1.7. The respondent's ages ranged from 18 to 62 years. The mean age was $35 \pm 8.8$ years. Most patients (85.9\%) were below 45 years of age. Majority of them were married (44.4\%), Christians (70\%), had some formal education (90.7\%), and earn less than N7500 (\$59) monthly, (55.1\%) (Refer Table 1). The level of knowl- edge, signs and symptoms of epilepsy was high with $57.8 \%$ and $25.9 \%$ demonstrating excellent and good knowledge respectively. The level of knowledge on the causes, signs and symptoms of epilepsy was very poor with only $9.3 \%$ knowing that it is a brain disorder while $66.7 \%$ attributes it to witchcraft, curse from above, 58.5\%; evil spirits, 39.6\% and micro organisms (germs), $25.9 \%$ (Table 2).

The level of knowledge of AED was high with 78.6\% (Table 3). The level of adherence to AED was $32.6 \%$. There was significant association between knowledge of AED and adherence to therapy $(p=0.00385)$ but there was no association between age $(p=0.067)$, sex $(p=$ $0.182)$ educational status $(p=0.688)$, income $(p=0.519)$ religion $(p=0.69)$ and place of residence $(p=0.157)$ with AED adherence. The reasons for non-adherence were as a result of forgetfulness, AED-induced fatigue and being away from home (Figure 2).

Table 4 shows respondents knowledge of the source of information of Antiepileptic therapy (AED) while Table 5 shows respondents' knowledge of Antiepileptic therapy (AED) when to start treatment after diagnosis.

Out of 144 respondents, $64.8 \%$ believe that drugs can cure the disease, $20.8 \%$ believe that traditional herbs can cure it while $14.4 \%$ believe in mystical ways for the cure (Figure 1).

As shown in Figure 2, out of 182 respondents that missed pills, 74 (40.7\%) said it was due to forgetfulness. 47 (25.8\%) complain of pill fatigue and being away from home was the reason in 22 (12.1\%).

Figure 3 shows factors influencing the distribution of respondent's perception to efficacy of AED therapy.

\section{Discussion}

The objective of this study was to assess factors influencing adherence to antiepileptic drugs (AEDs). It is of note that non-adherence in patients on AEDs is the strongest predictor of failure and more than 95\% adherence may be necessary to adequately suppress the seizure, this means that missing more than one dose of a regimen per week may be enough to cause treatment failure and trigger seizures. The challenges of adherence to AEDs is a central issue of concern and it is clear from literature that factors that influence a patient's ability to adhere are multiple and complex.

Medication adherence is often a challenge in the management of epilepsy. Adherence is even more difficult when taking multiple drugs with different dosing requirements and severe, unpleasant side effects such as skin rashes, hunger, nerve damage and changes in body composition. Many people with epilepsy also have other complicating factors in their lives, including mental 
Table 1. Socio demographic characteristics of respondents ( $N=270)$.

\begin{tabular}{|c|c|c|}
\hline Characters & No. & $\%$ \\
\hline \multicolumn{3}{|l|}{ Age } \\
\hline $18-25$ & 17 & 6.3 \\
\hline $26-44$ & 215 & 79.6 \\
\hline $45^{+}$ & 38 & 14.1 \\
\hline Total & 270 & 100.0 \\
\hline \multicolumn{3}{|l|}{ Sex } \\
\hline Male & 98 & 36.3 \\
\hline Female & 172 & 63.7 \\
\hline Total & 270 & 100.0 \\
\hline \multicolumn{3}{|l|}{ Marital Status } \\
\hline Single & 96 & 35.6 \\
\hline Married & 120 & 44.4 \\
\hline Widowed & 37 & 13.7 \\
\hline Divorced & 10 & 3.7 \\
\hline Separated & 7 & 2.6 \\
\hline Total & 270 & 100.0 \\
\hline \multicolumn{3}{|l|}{ Educational Level } \\
\hline None/informal & 25 & 9.3 \\
\hline Primary & 40 & 14.8 \\
\hline Secondary and above & 205 & 75.9 \\
\hline Total & 270 & 100.0 \\
\hline \multicolumn{3}{|l|}{ Religion } \\
\hline Christianity & 189 & 70.0 \\
\hline Islam & 81 & 30.0 \\
\hline Total & 270 & 100.0 \\
\hline \multicolumn{3}{|l|}{ Occupation } \\
\hline Farming & 13 & 4.8 \\
\hline Business man & 51 & 18.9 \\
\hline Students & 34 & 12.6 \\
\hline House wife & 54 & 20.0 \\
\hline Unskilled labourer & 14 & 5.2 \\
\hline Skilled labourer & 52 & 19.3 \\
\hline Unemployed Labourer & 35 & 13.0 \\
\hline Others & 17 & 6.3 \\
\hline
\end{tabular}

\begin{tabular}{|c|c|c|}
\hline Total & 270 & 100.0 \\
\hline \multicolumn{3}{|l|}{ Tribe } \\
\hline Hausa & 60 & 22.2 \\
\hline Fulani & 9 & 3.3 \\
\hline Yoruba & 28 & 10.4 \\
\hline Igbo & 33 & 12.2 \\
\hline Kataf & 20 & 7.4 \\
\hline Kaje & 22 & 8.2 \\
\hline Gwari & 16 & 5.9 \\
\hline Nupe & 12 & 4.4 \\
\hline Idoma & 21 & 7.8 \\
\hline Tiv & 22 & 8.2 \\
\hline Yakuur & 3 & 1.1 \\
\hline Kanuri & 4 & 1.5 \\
\hline Ijaw & 9 & 3.3 \\
\hline Ebira & 11 & 4.1 \\
\hline Total & 270 & 100.0 \\
\hline \multicolumn{3}{|l|}{ Residency } \\
\hline Within Kaduna town & 227 & 84.1 \\
\hline Outside Kaduna town & 43 & 15.9 \\
\hline Total & 270 & 100.0 \\
\hline \multicolumn{3}{|l|}{ Monthly Income } \\
\hline$<$ N7500 & 160 & 59.3 \\
\hline N7501 - N10,000 & 60 & 22.2 \\
\hline N10,001 - N20,000 & 30 & 11.1 \\
\hline $\mathrm{N} 20,001+$ & 20 & 7.4 \\
\hline Total & 270 & 100.0 \\
\hline
\end{tabular}

Table 2. Respondents knowledge of the causes, signs and symptoms of Epilepsy $(\mathrm{N}=270)$.

\begin{tabular}{lcc}
\hline \multicolumn{1}{c}{ Characters } & No. & $\%$ \\
\hline Perceived cause of Epilepsy & & \\
Witchcraft/Ghosts & 180 & 66.7 \\
Curse from above & 158 & 58.5 \\
Evil Spirit & 107 & 39.6 \\
Micro organism (Germs) & 70 & 25.9 \\
Inheritance/Brain disorder & 25 & 9.3 \\
\hline
\end{tabular}


Table 3. Respondents level of knowledge of ART.

\begin{tabular}{ccc}
\hline Level of knowledge & No & $\%$ \\
\hline Excellent $(5-6)$ & 212 & 78.6 \\
Good $(3-4)$ & 48 & 17.7 \\
Poor $(<2)$ & 10 & 3.7 \\
Total & 270 & 100 \\
\hline
\end{tabular}

Table 4. Respondents Knowledge of the source of information of Antiepileptic therapy $(\mathrm{N}=\mathbf{2 7 0})$.

\begin{tabular}{lcc}
\hline \multicolumn{1}{c}{ Characters } & No. & $\%$ \\
\hline Source of information on Antiepileptic therapy & & \\
Community leader & 194 & 71.9 \\
Health workers & 173 & 64.1 \\
Friends/Neighbors & 79 & 29.3 \\
Religious leader & 64 & 23.7 \\
Radio/Television & 45 & 16.7 \\
\hline
\end{tabular}

Table 5. Respondents' knowledge of Antiepileptic therapy ( $N=270)$.

\begin{tabular}{lcc}
\multicolumn{1}{c}{ Characters } & No. & $\%$ \\
\hline Time of commencing AEDs & & \\
Immediately when diagnosed & 117 & 43.3 \\
$<6$ months & 10 & 3.7 \\
$>12$ months & 42 & 15.6 \\
No response & 101 & 37.01 \\
Number of AEDs combination to be taken & & \\
One & 5 & 1.9 \\
Two & 29 & 10.7 \\
Three and above & 231 & 85.6 \\
No response & 5 & 1.9 \\
\hline
\end{tabular}

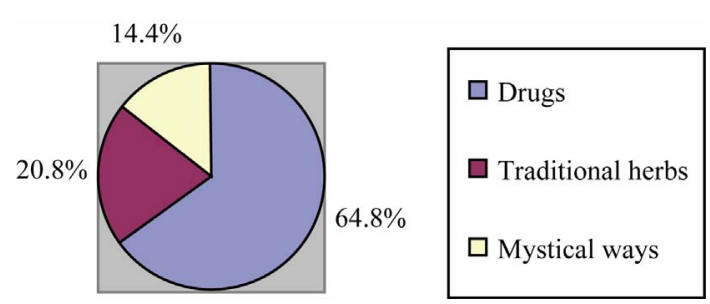

Figure 1. Respondents knowledge of those that believe it has control $(n=144)$. health issues, economic worries, lack of stable housing and alcohol or drug use, making it difficult to prioritize adherence. In our study, we found that adherence barriers such as regimen-specific issues, such as the complexity of the treatment and taking many pills at different times, as well as side effects of the medication, can lead persons to miss doses. Scheduling demands such as work, travel, forgetfulness and mealtimes can also be barriers (Altice FL et al.) [7].

Social and psychological factors influence adherence. Mental health issues (such as depression or psychological distress), attitudes toward treatment and toward epilepsy, and support from health care workers, family and friends are key to adherence. Positive responses promote adherence and negative responses (lack of support, pessimism, etc.) can make it more difficult to adhere to treatment regimens.

Institutional factors such as clinic setting and access to reliable health care and medication affect adherence.

Factors that promote adherence are pleasantness of the clinic, convenience of scheduling, confidentiality and availability of transportation as we discovered in our study that stigmatization can also affect drug adherence. Patients on higher income have been shown to have less difficulty with adherence, but we know that poverty is an increasing feature of epilepsy especially those in the third world where many lives below poverty line. The findings in this study as shown in Table 1, showed that 59.3\% earn below N7500 (\$59), this will affect even the medication and clinic visits cost and subsequently affect an already stretched budget.. Age did not show any signifycant correlation to the adherence rate.

The gender inequality does not affect the adherence, the study showed that $63.7 \%$ were female compared to 36.3\% male as shown in Table 1, the female preponderance in the study may be explained, since women were more vulnerable than men. Female are always serious to matters related to health, the male are more conscious about the stigmatization. Most female are of lower socio economic status therefore will prefer to take medication if it is cheaper and affordable. Some studies showed that lower level of general education and poorer literacy impacts negatively on some patient's ability to adhere $[5,6]$ while in some higher level of education has a positive impact [8] but from this study, the educational status does not have impact on the adherence rate to AEDs, may be as a result of choices in which the respondents may differ in fundamental ways of interest on attitudinal and behavioral dimensions as well as demographic dimensions.

Indicators of poor adherence to a medication regimen are a useful resource for physicians to help identify pa- 


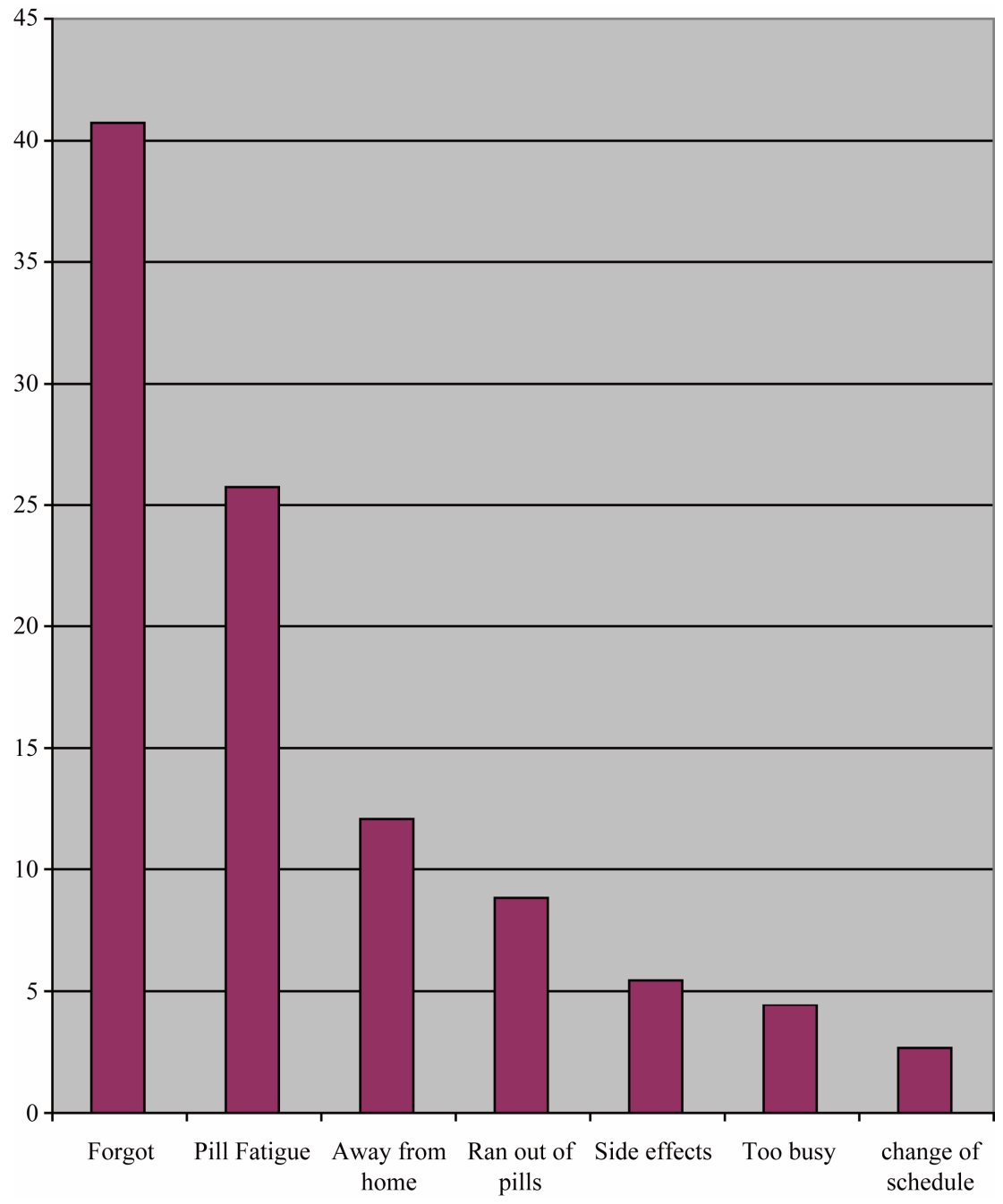

Figure 2. Reasons for miss of pill $(\mathrm{N}=182)$.
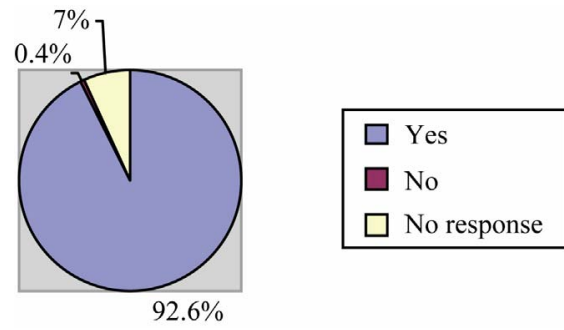

Figure 3. Distribution of respondents perception to efficacy of AED therapy.

tients who are most in need of interventions to improve adherence $[9,10]$.

Patient's beliefs about their illness and the effectiveness of medication are predictive of adherence [11,12] and can prolong life and the understanding of poor use of drug which can lead to treatment failure all impact fa- vourably on adherence. Table 6 showed that majority (98.5\%) knew correctly the causes but still did not adhere to the therapy possibly because of poor comprehension of the danger associated with non-adherence.

\section{Conclusions}

Epilepsy, one of the most important non-communicable neurological illnesses, is particularly under-resourced and under-treated in the developing world. Epidemiological studies have made it clear that the magnitude of the problem makes it a public health priority. Adherence to AED was low despite high level of knowledge due to forgetfulness, fatigue and being away from home, therefore a need for mounting adherence counseling in the clinic and health educational interventions to improve adherence in our rural communities. Large numbers of people are at risk of morbidity and mortality, mainly be- 
Table 6. Respondents level of knowledge about Epilepsy.

\begin{tabular}{cccc}
\hline \multicolumn{2}{c}{ Level of knowledge } & No & $\%$ \\
\hline Excellent & $32-42$ & 156 & 57.8 \\
Good & $21-31$ & 70 & 25.9 \\
Fair & $10-20$ & 40 & 14.8 \\
Poor & $<9$ & 4 & 1.5 \\
Total & & 270 & 100 \\
\hline
\end{tabular}

cause of difficulties with treatment infrastructure and the availability of suitable drugs. However, people with epilepsy need more than drug treatment because their local cultural context adds social and economic burdens to the physical burden of their seizures. The education of health workers, patients, and the wider community is therefore essential and further exploration of the relationship between clinical outcomes and other non-drug self-management strategies is needed.

Adherence to AED was low despite high level of knowledge due to forgetfulness, non-availability, being expensive, fatigue and being away from home, therefore a need for mounting adherence counseling in the clinic and health educational interventions to improve adherence in our rural communities where the disease cannot be managed. Further exploration of the relationship between clinical outcomes and other non-drug self-management (traditional) strategies is needed.

\section{Limitations of the Study}

1) Time constraints-A more accurate information on adherence from a prospective follow-up of patients. Unfortunately because of time constraint this was not possible.

2) Local works on adherence to AEDs are limited; therefore few locally conducted studies were reviewed.

\section{REFERENCES}

[1] World Health Organization, "The Global Campaign against Epilepsy,” Information Pack for the Launch of the
Global Campaign's Second Phase, Geneva, 12-13 February 2001.

[2] G. L. Birbeck, "Neurologic Disease in a Rural Zambian Hospital,” Tropical Doctor, Vol. 31, 2001, pp. 82-85.

[3] M. Placencia, et al., "The Characteristics of Epilepsy in a Largely Untreated Population in Rural Ecuador,” Journal of Neurology, Neurosurgery, and Psychiatry, Vol. 57, No. 3, 1994, pp. 320-325. doi:10.1136/jnnp.57.3.320

[4] World Health Organization, "The Global Burden of Mental and Neurological Problems," WHO Fact Sheet No. 217, Geneva, 1999.

[5] World Health Organization, "Raising Awareness, Fighting Stigma, Improving Care,” WHO Press Release WHO/67, Geneva, 1999.

[6] G. Birbeck, "Interventions to Reduce Epilepsy-Associated Stigma," Psychology, Health \& Medicine, Vol. 11, No. 3, 2006, pp. 364-366. doi:10.1080/13548500600595343

[7] F. L. Altice, F. Mostashari and G. H. Friedland, "Trust and Acceptance of and Adherence to Antiretroviral Therapy," Journal of Acquired Immune Deficiency Syndromes, Vol. 28, No. 1, 2001, pp. 47-58.

[8] V. Gordillo, J. Del Amo, V. Soriano, et al., "Sociodemographic and Psychological Variables Influencing Adherence to Antiretroviral Therapy," Aids, Vol. 13, No. 13, 1999, pp. 1763-1769. doi:10.1097/00002030-199909100-00021

[9] D. Ciccarone, D. Bangsberg, J. Bamberger, et al., "HIVRelated Hospitalization before and during Participation in 'Action Point' an Adherence Case Management Program," American Public Health Association Conference, Chicago, January 2003.

[10] J. S. Benner, R. J. Glynn, H. Mogun, P. J. Neumann, M. C. Weinstein and J. Avorn, "Long-Term Persistence in Use of Statin Therapy in Elderly Patients,” JAMA: The Journal of the American Medical Association, Vol. 288, No. 4, 2002, pp. 455-461. doi:10.1001/jama.288.4.455

[11] M. L. Zoler, Clinical Psychiatry News, January 2008. http://www.medpagetoday.com/Neurology/Seizures/9869

[12] C. Y. Wang and J. M. Buelow, "Medication-Taking Behavior of Patients with Epilepsy," US Neurological Disease 2006 Issue II, October 2008. 